06

\title{
Исследование влияния обработки лазерными импульсами наносекундной длительности на микроструктуру и сопротивление усталости технически чистого титана
}

\author{
(С) Ю.Р. Колобов ${ }^{1}$, С.С. Манохин ${ }^{1, \uparrow}$, В.И. Бетехтин ${ }^{2}$, А.Г. Кадомцев ${ }^{2}$, М.В. Нарыкова ${ }^{2}$, Г.В. Одинцова ${ }^{3}$, \\ Г.В. Храмов ${ }^{4}$
}

${ }^{1}$ Институт проблем химической физики РАН, Черноголовка, Московская обл., Россия

${ }^{2}$ Физико-технический институт им. А.Ф. Иофффе РАН, Санкт-Петербург, Россия

${ }^{3}$ Университет ИТМО, Санкт-Петербург, Россия

${ }^{4}$ Белгородский государственный национальный исследовательский университет, Белгород, Россия

ฯ E-mail: manohin@icp.ac.ru

Поступило в Редакцию 16 сентября 2021 г.

В окончательной редакции 28 сентября 2021 г.

Принято к публикации 28 сентября 2021 г.

Исследовано влияние обработки лазерными импульсами наносекундной длительности на сопротивление усталости пластинчатых образцов рекристаллизованного (размер зерен порядка $2-3 \mu \mathrm{m}$ ) технически чистого титана (марки ВТ1-0) при воздействии циклической нагрузки растяжением. Установлена возможность повышения сопротивления усталостному разрушению исследованных образцов за счет импульсной лазерной обработки более чем на $100 \%$ при испытаниях на базе до $10^{6}$ циклов. Представлены результаты исследований методами растровой и просвечивающей электронной микроскопии микроструктуры подповерхностного слоя исследуемого материала после воздействия наносекундным лазерным облучением и последующих усталостных испытаний. Сделано предположение о проявлении процесса направленной перпендикулярно поверхности образца кристаллизации расплавленного лазерным пучком тонкого подповерхностного слоя.

Ключевые слова: титан, поверхность, импульсное наносекундное лазерное облучение, ударно-волновое воздействие, усталостные свойства.

DOI: 10.21883/PJTF.2022.02.51913.19025

Одним из перспективных направлений в области создания новых технологий обработки металлических материалов медицинского назначения является поверхностная модификация с использованием концентрированных потоков энергии, в том числе лазерного облучения [1-3]. Подавляющее большинство широко применяющихся в производственной практике способов модификации поверхностей материалов связано со значительным разогревом их приповерхностных слоев или всего объема материала. В значительной степени избежать этого позволяет активно развиваемый в последнее десятилетие перспективный метод обработки поверхностей металлических материалов лазерными импульсами короткой (пико-, нано- и субнаносекундной) и ультракороткой (субпико- и фемтосекундной) длительности [1-3]. Развивающиеся при таком воздействии процессы, связанные с изменением рельефа поверхности и фазово-структурными превращениями в тонких подповерхностных (толщиной $1-5 \mu \mathrm{m}$ ) слоях, позволяют формировать уникальный комплекс физико-химических и механических свойств указанных областей материалов. Варьируя параметры лазерного облучения, можно контролируемым образом изменять рельеф поверхности от макро- до наноуровня, в том числе создавая многомодальную шероховатость, с которой связано проявле- ние супергидрофобных или супергидрофильных свойств поверхности. Известно, что переход от режима абляции материала поверхности к режиму ударно-волной обработки (лазерная ковка, в англоязычной литературе peening) позволяет улучшать механические характеристики как подповерхностных, так и приповерхностных слоев материалов до глубины от одного до нескольких сотен микрометров [1,4]. Однако вопрос о влиянии наносекундного лазерного облучения на механические свойства при циклическом нагружении титановых сплавов на данный момент малоизучен. В настоящей работе проведено исследование влияния наносекундного лазерного облучения на сопротивление усталости рекристаллизованного технически чистого титана, а также изучение особенностей изменения рекристаллизованной структуры приповерхностного слоя исследуемого сплава в процессе наносекундного лазерного облучения и испытаний на усталость.

В качестве материала для исследований выбран технически чистый титан марки ВТ1-0, химический состав которого приведен в таблице.

Для исследования усталости использовались плоские образцы в форме сечения двутавра с толщиной рабочей базы $1 \mathrm{~mm}$, шириной $3 \mathrm{~mm}$ и длиной $40 \mathrm{~mm}$, изготовленные методом электроэрозионной резки на 
Химический состав сплава ВТ1-0 (на основе Ті)

\begin{tabular}{c|c|c|c|c|c|c|c}
\hline & \multicolumn{7}{c}{ Содержание элементов, wt.\% } \\
\cline { 2 - 8 } & $\mathrm{Al}$ & $\mathrm{Fe}$ & $\mathrm{Si}$ & $\mathrm{O}$ & $\mathrm{C}$ & $\mathrm{N}$ & $\mathrm{H}$ \\
\cline { 2 - 8 } Требование & $<0.7$ & $<0.25$ & $<0.1$ & $<0.2$ & $<0.07$ & $<0.04$ & $<0.006$ \\
Фактически & $<0.01$ & $<0.12$ & $<0.01$ & $<0.14$ & $<0.01$ & $<0.01$ & $<0.01$
\end{tabular}

установке „AQ300L“. Испытания на усталость в режиме циклического нагружения проводились на оборудовании Центра наноструктурных материалов и нанотехнологий НИУ „БелГУ“ с использованием испытательной машины Instron Electropulse E3000, оснащенной электромагнитным приводом. Как известно, частота нагружения подбирается в соответствии с амплитудно-частотной характеристикой (АЧХ), которая зависит от жесткости испытываемого образца. Частота испытаний $15 \mathrm{~Hz}$ в настоящей работе была выбрана в области, где отсутствуют искажения синусоидального характера АЧХ, которые наблюдаются при более высоких частотах при комнатной температуре.

Структурные исследования проводились на просвечивающих электронных микроскопах (ПЭМ) Tecnai G2 F20 S-TWIN, FEI TecnaiOsiris при ускоряющем напряжении $200 \mathrm{kV}$. Подготовка вырезаемых перпендикулярно поверхности образца тонких фольг (ламелей) для ПЭМ осуществлялась методом ионного утонения сфокусированным ионным пучком в колонне растрового электронно-ионного микроскопа FEI Scios.

Лазерная обработка образцов проводилась под слоем воды (толщиной порядка $2 \mathrm{~mm}$ ) на установке „Минимаркер-2“ со следующими параметрами облучения: длина волны $\lambda=1064 \mathrm{~nm}$, длительность импульса $\tau \sim 100 \mathrm{~ns}$, энергия в импульсе $E \approx 10^{-3} \mathrm{~J}$, частота следования импульсов $v=50 \mathrm{kHz}$, скорость сканирования лазерного пучка $v=1500 \mathrm{~mm} / \mathrm{s}$, плотность мощности одиночного импульса $F \sim 1 \mathrm{GW} / \mathrm{cm}^{2}$. Лазерное облучение образцов проведено в сканирующем режиме с заданным системой управления максимально плотным размещением кратеров на поверхности без их наложения (в точку падает один импульс, без перекрытия). Диаметр сфокусированного на поверхности лазерного пучка составлял $35 \mu \mathrm{m}$.

Для приготовления тонкой фольги (ламели) из подповерхностного слоя исследуемого материала методом „cross-section“ использовался растровый электронноионный микроскоп FEI Scios Dual Beam (ЦКП ФНИЦ „Кристаллография и фотоника“). Ламели вырезались из середины отдельно расположенных кратеров в виде расплывшейся капли расплава, образовавшихся при воздействии одиночного импульса. По периферии таких кратеров отчетливо наблюдается выпуклый валик с овальными краями, дополнительно свидетельствующий о локальном плавлении.

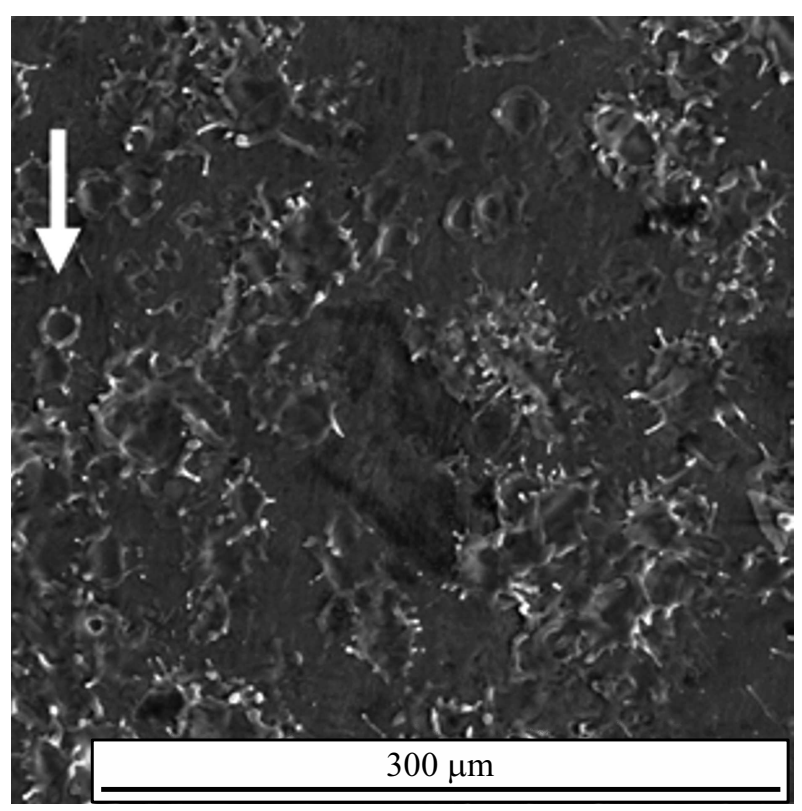

Рис. 1. Микроструктура поверхности образцов сплава ВТ1-0 в исходном рекристаллизованном состоянии после обработки лазерными импульсами наносекундной длительности под слоем воды. Стрелкой показан одиночный кратер, характерный для воздействия одного импульса. Плотность мощности одиночного импульса $\sim 1 \mathrm{GW} / \mathrm{cm}^{2}$.

При выбранной в работе скорости сканирования лазерного пучка по поверхности материала (под слоем воды) в металлографическом микроскопе можно наблюдать как отдельные, так и перекрывающиеся кратеры (рис. 1). Как известно, возникновение кратеров связано с тем, что при плотности мощности лазерного импульса выше порога появления абляции происходит микровзрыв с образованием кратера на поверхности образца и светящейся плазмы вместе с разлетающимися твердыми и жидкими частицами. Площадь, занятая перекрывающимися кратерами, определялась с помощью свободно распространяемой аналитической программы „ImageJ“. Для выполнения такого анализа изображения обрабатывались путем повышения контраста и значительного увеличения яркости средних тонов. Такая операция приводит к тому, что на изображении остаются видимыми только кратеры, что делает возможным расчет занятой кратерами площади поверхности, которая составляла порядка 80\%. Рельеф в области лазерной обработки 


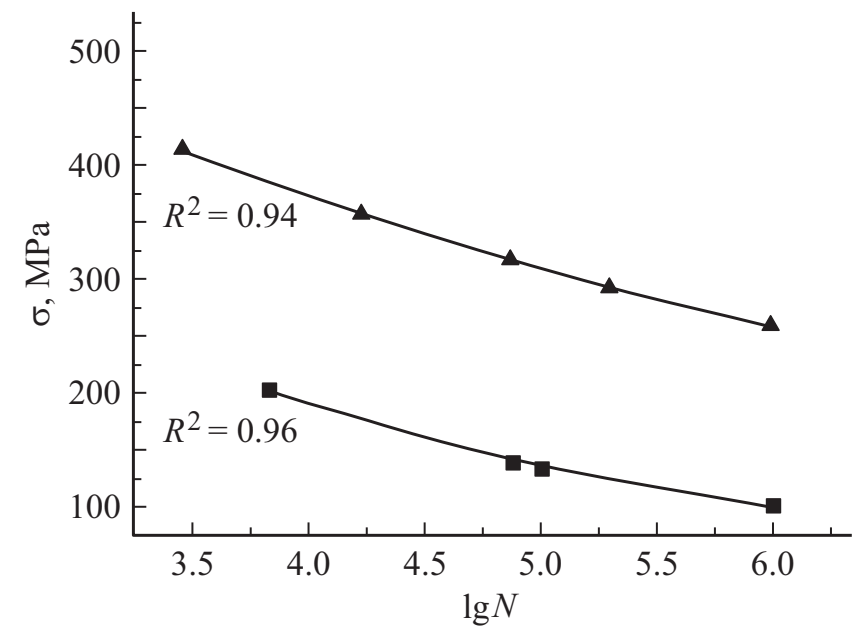

Рис. 2. Кривые усталости для образцов сплава ВТ1-0 в исходном рекристаллизованном состоянии (квадраты) и после обработки лазерными импульсами наносекундной длительности (треугольники) в воде (с плотностью мощности одиночного импульса $\sim 1 \mathrm{GW} / \mathrm{cm}^{2}$ ).

был исследован на поперечном срезе кратера, который был получен с применением сфокусированного ионного пучка в колонне растрового электронного микроскопа. Значения глубины кратера и высоты окружающего его валика, измеренные по отношению к исходному уровню поверхности, составляют 6 и $0.5 \mu \mathrm{m}$ соответственно.

Для определения предела выносливости по результатам экспериментов были построены (рис. 2) зависимости максимального напряжения в цикле от числа циклов до разрушения (диаграмма Вёллера) для образцов рекристаллизованного титана ВТ1-0 в исходном состоянии и после предварительной обработки поверхности лазером. Как видно из рис. 2, для всей области задаваемых напряжений образцы после обработки наносекундным лазерным облучением в среднем выдерживают значительно большее напряжение при одинаковом количестве циклов до разрушения, чем в исходном состоянии без лазерной обработки. Таким образом, модификация подповерхностного слоя исследуемых образцов наносекундным лазерным облучением приводит к существенному повышению сопротивления усталостному разрушению.

На изображениях, полученных с помощью просвечивающей электронной микроскопии, после наносекундного лазерного воздействия и усталостных испытаний в приповерхностном слое наблюдается модифицированный слой глубиной порядка $1-2 \mu \mathrm{m}$ (рис. 3, $a, b)$. Данный слой сформировался в результате лазерной обработки импульсами наносекундной длительности под слоем воды, поскольку в его микроструктуре не обнаруживается каких-либо отличий от наблюдаемой после лазерного облучения до испытаний на усталость (рис. 3,d). Микроструктура исследуемого сплава представляет собой кристаллиты удлиненной пластинчатой формы шириной порядка $300 \mathrm{~nm}$ и длиной $2-3 \mu \mathrm{m}$. Кристаллиты вытянуты преимущественно в направлении, перпендикулярном поверхности образца, как это и должно быть при кристаллизации с теплоотводом в данном направлении. На основе картины микродифракции (рис. $3, c)$ можно сделать заключение, что разориентация между кристаллитами соответствует малоугловой (угол разориентировки менее $15^{\circ}$ ). Расположение рефлексов не соответствует двойниковой разориентации, поскольку при двойниковании в рассматриваемой ориентации кристаллита $[000 \overline{1}]$ (рис. $3, c)$ наблюдались бы двойниковые рефлексы, расположенные симметрично плоскости типа (1010) [5]. Таким образом, близкорасположенные

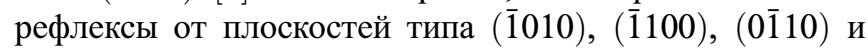
других свидетельствуют о наличии малоугловых границ между соседними кристаллитами. Можно предположить, что такая разориентация кристаллитов связана с их зарождением из расплава на поликристаллической подложке с отчетливо выраженной кристаллографической текстурой. Таким образом, кристаллическая подложка, на которой кристаллизуются и растут вытянутые монокристаллические структурные элементы (кристаллиты), задает кристаллоструктурное соответствие с подложкой наблюдаемых блоков с малоугловой взаимной разориентацией. Такое обычно наблюдается при росте блочных монокристаллов из жидкой фазы на твердофазной кристаллической подложке. Вероятно, в зависимости от текстуры прокатки, задающей преимущественно тип кристаллографической плоскости (на которой будет формироваться зародыш кристаллизации), можно получать те или иные кристаллические структуры с заданной кристаллографической ориентацией.

Обнаружено, что обработка экспериментальных образцов рекристаллизованного технически чистого титана (марки ВТ1-0) в виде пластин лазерными импульсами наносекундной длительности приводит к значительному повышению условного предела выносливости при приложении циклической нагрузки растяжением и количестве циклов до $10^{6}$. Установлено, что данный эффект связан с формированием в тонком (толщиной порядка $2 \mu \mathrm{m})$ подповерхностном слое в процессе воздействия наносекундных лазерных импульсов пластинчатой микроструктуры с вытянутыми (преимущественно перпендикулярно поверхности образца) элементами микроструктуры, имеющими поперечный размер порядка $300 \mathrm{~nm}$ и длину $2-3 \mu \mathrm{m}$. Формирование охарактеризованной выше субмикрокристаллической структуры подтверждает установленное ранее проявление процесса направленной перпендикулярно поверхности образца (в направлении теплоотвода) кристаллизации расплавленного лазерным пучком тонкого подповерхностного слоя.

Известно, что измельчение структуры металлов и сплавов до наномасштабного уровня хотя бы в одном направлении препятствует зарождению и распространению трещин, которое при усталости в исследованном 

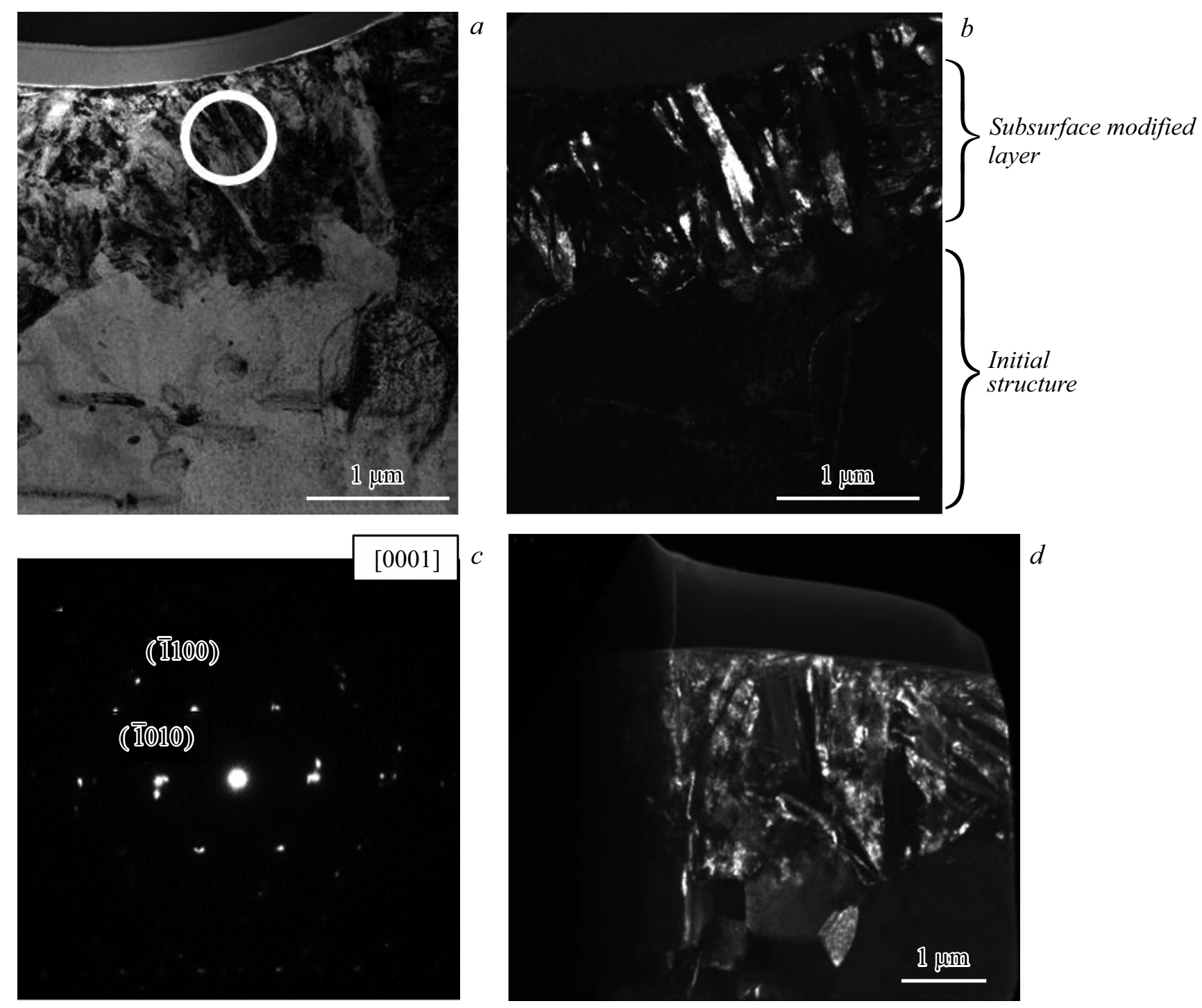

Рис. 3. Микроструктура образца технически чистого титана (ВТ1-0) в исходном рекристаллизованном состоянии после предварительной обработки наносекундным лазерным пучком под водой (при плотности мощности одиночного импульса $\left.\sim 1 \mathrm{GW} / \mathrm{cm}^{2}\right)$ и усталостных испытаний $\left(1 \cdot 10^{6}\right.$ циклов, напряжение в цикле $\left.100 \mathrm{MPa}\right) . a-$ светлопольное; $b-$ темнопольное изображение (просвечивающая электронная микроскопия); $c$ - микродифракция (область ее получения отмечена на части $a$ ); $d$ - темнопольное изображение исходного рекристаллизованного образца (до облучения), приведенное для сравнения (просвечивающая растровая электронная микроскопия).

диапазоне циклов нагружения преимущественно происходит в тонких приповерхностных слоях.

\section{Благодарности}

Структурные исследования проводились с использованием научного оборудования ЦКП ФНИЦ „Кристаллография и фотоника“ РАН (Москва).

\section{Финансирование работы}

Работа в основной части, связанной с исследованием структуры сплава ВТ1-0 после наносекундного лазерного воздействия, поддержана Российским научным фон- дом (проект № 19-12-00221), в дополнительной части, связанной с определением параметров рельефа поверхности, в том числе геометрических размеров одиночных кратеров на поверхности образцов исследуемого сплава, выполнена при финансовой поддержке в рамках государственного задания (номер госрегистрации АААА-А19119100800130-0).

\section{Конфликт интересов}

Авторы заявляют, что у них нет конфликта интересов. 


\section{Список литературы}

[1] Ю.Р. Колобов, Изв. вузов. Физика, 61 (4), 11 (2018). [Yu.R. Kolobov, Russ. Phys. J., 61 (4), 611 (2018).

DOI: $10.1007 / \mathrm{s} 11182-018-1440-4]$.

[2] V.P. Veiko, Yu.Yu. Karlagina, E.E. Egorova, E.A. Zernitskaya, D.S. Kuznetsova, V.V. Elagin, G.V. Odintsova, J. Phys.: Conf. Ser., 1571 (1), 012010 (2020). DOI: $10.1088 / 1742-6596 / 1571 / 1 / 012010$

[3] А.А. Ионин, С.И. Кудряшов, А.А. Самохин, УФН, 187 (2), 159 (2017). DOI: 10.3367/UFNr.2016.09.037974 [A.A. Ionin, S.I. Kudryashov, A.A. Samokhin, Phys. Usp., 60 (2), 149 (2017). DOI: 10.3367/UFNe.2016.09.037974].

[4] W. Jia, Q. Hong, H. Zhao, L. Li, D. Han, Mater. Sci, Eng. A, 606, 354 (2014). DOI: 10.1016/j.msea.2014.03.108

[5] P.G. Partridge, Met. Rev., 12 (1), 169 (1967).

DOI: $10.1179 / \mathrm{mtl}$.1967.12.1.169 